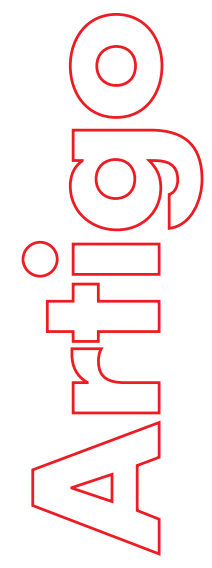

\title{
CONSTRUINDO MAPAS FEMINISTAS DA CIDADE DE GOIANIA (GO)
}

Talita Cabral

p. $32-50$

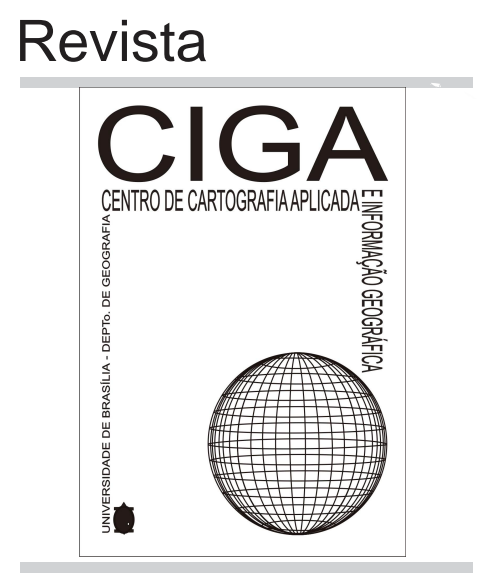

Revista Eletrônica:

Tempo - Técnica - Território,

V.7, N.2 (2016), 32:50

ISSN : 2177-4366

DOI: https://

doi.org/10.26512/

ciga.v7i2.19095
Como citar este ar tigo:

Cabral, T. CONSTRUINDO MAPAS FEMINISTAS DA CIDADE DE GOIÂNIA (GO).

Revista Eletrônica: Tempo - Técnica - Território, v.7, n.2 (2016), p. 32:50

ISSN: 2177-4366. DOI: https://doi.org/10.26512/ciga.v7i2.19095

Disponível em: http://periodicos.unb.br/index.php/ciga

Este obra está licenciado com uma Licença Crea tive Commons Atribuição-NãoComer cial 4.0 Inter nacional. 


\title{
CONSTRUINDO MAPAS FEMINISTAS DA CIDADE DE GOIÂNIA (GO)
}

\author{
Talita Cabral \\ talita.geo@gmail.com
}

\begin{abstract}
RESUMO: Objetivo é construir mapas das ações feministas da cidade de Goiânia (GO). A metodologia adotada utiliza-se das narrativas de lideranças, por meio de entrevistas semiestruturadas com treze feministas e das técnicas de mapeamento participativo. Foram mapeados os locais e trajetos considerados importantes para as lutas das mulheres. Os pressupostos teóricos são baseados em leituras sobre cartografias e mapas participativos, sociais e/ou culturais. As atuações feministas são pensadas de maneira distinta em cada região da cidade. As mulheres consideram as diferentes regiões político-administrativas para a construção de suas atividades, assim como as diferenciações entre centro e periferia. Existem locais e regiões da cidade onde apenas alguns grupos específicos feministas atuam e outros, onde todos eles estão presentes, a exemplo, do Setor Central. Os mapas evidenciam os locais e percursos das ações das entrevistadas e seus coletivos e possibilitam iniciar uma reflexão sobre a relação entre as questões de gênero e a cidade.
\end{abstract}

Palavras-chaves: mapa; cartografia; grupos feministas; feministas; cidade.

\begin{abstract}
The goal is to construct maps of feminists actions in Goiania(GO). The chosen methodology use stories of leadership, by means of semi structured interviews with thirteen feminists and the interactive mapping techniques. Were mapped the places and routes considerate important in the woman fight. The theoretical suppositions are based in cartographic readings about cartography and interactive maps, social and/or cultural. The feminists actions are thought in a different way in each area of the city. The woman considerate the different political administrative areas to the construction of their activities, as the variations between center and periphery. There are places and locations of the city where only a few specific feminists groups act, and others where all of them are attending, as an example, the Central Sector. The maps highlight the places and paths of the actions of the interviews and their unions make it possible to begin a reflection about the relation between gender issues and the city.
\end{abstract}

Keywords: map; cartography; feminist groups; feminists; city.

Resumen: El objetivo es construir mapas de las acciones feministas de la ciudad de Goiânia (GO). La metodología adoptada se utiliza de las narrativas de liderazgos, por medio de entrevistas semiestructuradas con trece feministas y de las técnicas de mapeo participativo. Se asignaron los lugares y trayectos considerados importantes para las luchas de las mujeres. Los presupuestos teóricos se basan en lecturas sobre cartografías y mapas participativos, sociales y / o culturales. Las actuaciones feministas son pensadas de manera distinta en cada región de la ciudad. Las mujeres consideran las diferentes regiones político-administrativas para la construcción de sus actividades, así como las diferenciaciones entre centro y periferia. Hay lugares y regiones de la ciudad donde sólo algunos grupos específicos feministas actúan y otros, donde todos ellos están presentes, a ejemplo, del Sector Central. Los mapas evidencian los lugares y recorridos de las acciones de las entrevistadas y sus colectivos y posibilitan iniciar una reflexión sobre la relación entre las cuestiones de género y la ciudad

Palabras-clave: mapa; cartografía; grupos feministas; feministas; ciudad. 


\section{Introdução, Objetivo, Metodologia e discussão teórica}

O artigo é resultado parcial da pesquisa de doutorado, concluída em dezembro de 2016 (MACHADO, 2016), sobre cartografias feministas da cidade a partir dos processos de apropriação do espaço urbano de Goiânia (GO) realizados por diferentes mulheres militantes.

A cartografia é uma linguagem, corresponde à organização de signos na construção de uma mensagem. Também constitui uma forma de representação do espaço e dos processos espaciais. O mapa é a representação cartográfica da espacialidade do fenômeno. Ele é uma construção social, com uma intenção do sujeito de reconhecer uma ordem e tentar retirar dela um sentido.

Martinelli (1999) diz que em qualquer cultura, os mapas são formas manipuladas de saber, cujas imagens são carregadas de valor. Quando perguntam-se quais são os mapas que mais tem-se acesso, os mais utilizados para a construção de políticas públicas e quem são os(as) sujeitos(as) que constroem esses mapas, deve-se ter em mente as relações entre poder e sujeito nos processos de cartografar.

O mapa, produto gerado pela cartografia, é uma representação do espaço e compreende relações de poder construídas no processo de cartografar. Os mapas, através de seus códigos, convenções e procedimentos de organização e taxionomia operam como uma tecnologia do poder. Eles são seletivos e servem para disseminar e reforçar ideologias que, durante muito tempo, foram as dominantes. Santos (2010) complementa essa visão dizendo:

Da difusão de uma visão tecnicista e cartesiana de mundo, p. ex., pela forma como
ensinamos Cartografia. De uma forma de representação espacial, ela é
transformada em única forma de expressão espacial do mundo, critério de verdade
e de existências naturais e sociais, decorrente das possibilidades da racionalidade
técnica subjacente ao processo de elaboração dos mapas - que são, melhor dizendo,
limitados por esta racionalidade às formas científico-ocidentais de ver o mundo, de
expressar referenciais de espaço, de tempo e das existências sociais. Esta forma
como se trabalha e ensina a Cartografia Escolar dá aos mapas oficiais um caráter
de expressão da verdade que é poderoso instrumento de poder através da produção
de não existências de grupos sociais, conflitos, saberes, experiências e formas de
relação com o mundo. (SANTOS, 2010, p.150)

Opondo-se a forma de compreender o mapa exposto acima por Santos (2010), vem-se intensificando no Brasil o número de grupos sociais e culturais no campo, na floresta e na cidade que buscam as ferramentas cartográficas para realizar seus próprios mapeamentos. A partir do momento em que os grupos sociais e culturais subalternos começam a apropriar-se da produção de mapas, através dos mapeamentos participativos e da cartografia social, novas territorialidades 
emergem e são reconhecidas. Os sujeitos desses grupos mapeiam, reafirmando suas territorialidades específicas.

Os objetivos da cartografia social são diversos e as metodologias utilizadas também. Um dos objetivos é indicar, qualificar e problematizar os conflitos vivenciados, quais são as "agressões” e os sujeitos coletivos envolvidos. Também é evidenciar os impactos negativos das atividades existentes em suas localidades.

A cartografia participativa emerge num contexto caracterizado por um deslocamento da exclusividade e incontestabilidade da cartografia oficial do Estado, positivista e cartesiana, para um crescente número plural de práticas e experiências que dão outro sentido a cartografia.

Massey (2008) apresenta a visão de Huggan (1989) dizendo que as novas formas de cartografar (também a partir da cartografia participativa, social e /ou cultural) podem ao mesmo tempo representar atitudes rígidas do passado (como a localização de eventos em coordenadas x e y que ainda é importante e muito utilizada), mas também, ser retrabalhada a partir de dentro. Para Massey:

Nesses projetos, mapas podem ao mesmo tempo ser desconstruídos e, então reconstruídos, sob uma forma que desafie a reivindicação de singularidade, estabilidade e fechamento que caracterizam nossa noção (e, certamente, na maioria dos casos, a intenção) usual de representação cartográfica. (2008, p. 163)

O que acontece na produção de tais mapas são reimaginações das possibilidades de cartografar: "É um avanço da crítica dos mapas como “tecnologias de poder” para forçar nossa compreensão da própria forma do mapa” (MASSEY, 2008, p.164). Essas formas de cartografar indicam multiplicidade e tem como objetivo desorganizar o mapa ocidental clássico, a sua uniformidade singular ao apontar os “pontos cegos” (p.164) e os “esquecimentos” (p.164) trazidos por eles.

Massey (2008) afirma que mesmo denunciando os pontos cegos e esquecimentos presentes na cartografia ocidental tradicional, essa cartografia fica “dentro da imaginação de superfície” (p.165). O que significa “imaginar o espaço sendo mapeado - que é um espaço como simultaneidade - como o produto de estruturas horizontais sobrepostas, em vez de uma coexistência contemporânea plena e em devir” (p.165). Quando ocorre o mapeamento “não percebemos as rupturas do espaço, o encontro com a diferença.” (p.165). Os mapas são limitados e trazem um recorte delimitado de tempo e espaço, assim como dependem da experiência, memória e vivência com os eventos mapeados realizadas por quem os constroem.

Apesar da importância da apropriação da cartografia por um número maior de pessoas e grupos sociais, principalmente a partir das cartografias participativas, para Acselrad (2010), no entanto, ela já nasce marcada pela ambiguidade e estabelecer posturas críticas frente o processo de 
cartografar é essencial. Num contexto da última década em que se tornou muito comum a prática de mapeamentos participativos incentivados ou promovidos por diferentes ONGs (Organizações NãoGovernamentais), agências multilaterais de desenvolvimento e empresas, e num contexto de disputas territoriais, o autor afirma que:

Construída para dar a palavra às comunidades de base e grupos desfavorecidos integrando, inclusive, segundo alguns, um projeto territorializado de contra-cultura política - sua realização mostra-se dependente da estrutura de poder na qual ele se instaura. No vasto aspecto de experiências conhecidas no mundo, podemos verificar que elas podem estar associadas à afirmação identitária e territorial de grupos subalternos, assim com a fundamentação cognitiva da gestão racional de recursos naturais, a mecanismos de explicitação de conflitos sócio-territoriais e ambientais ou a formas de antecipação dos mecanismos para fins de controle estatal do território. (ACSELRAD, 2010, p. 9 e 10)

Por isso, torna-se importante que os sujeitos no processo de mapeamento participativo questionem constantemente: para quem e para que as informações vão servir?

O aumento do uso da cartografia participativa, cartografia social ou cartografia cultural resultaram em inúmeros trabalhos sobre o tema nas áreas de geografia, antropologia e outras. No período de 1992-2010 existiam experiências em Cartografia Social e Mapeamentos Participativos em todas as regiões do Brasil (ACSELRAD, 2010). No mapeamento realizado por Acselrad (2010), o estado de Goiás, juntamente com o Distrito Federal, Rio Grande do Norte e Sergipe eram os únicos sem registro dessas experiências.

Objetivo do artigo é construir mapas das ações feministas da cidade de Goiânia. A metodologia adotada utiliza-se das narrativas de lideranças, por meio de entrevistas semiestruturadas com treze feministas e das técnicas de mapeamento participativo. Foram mapeados os locais e trajetos considerados importantes para as lutas das mulheres e eles possuem distintas temporalidades (pretéritas, presentes e futuras) e espacialidades (temporárias, fixas e fluidas).

No primeiro mapeamento, foi utilizada uma base cartográfica já existente (com limite de bairros, quadras, ruas e parques), numa escala do município de Goiânia ${ }^{1}$. Agregou-se a esta base informações (de parte) das ações na cidade realizadas pelas mulheres feministas entrevistadas e dos seus coletivos.

O primeiro limite dos mapas surge no processo de escolha das entrevistadas e durante as entrevistas, pois elas dependem do fluxo de memórias e dos humores das entrevistadas. O segundo limite foi a limitação das experiências e vivências da pesquisadora com as entrevistadas e os grupos aos quais elas pertenciam. Não se pode experienciar todos os encontros e manifestações que aconteceram no período da pesquisa, porque as ações dos grupos são múltiplas e nem tudo que

\footnotetext{
1 Foi utilizado para a construção do mapa, o programa gratuito de geoprocessamento QGIS (anteriormente conhecido como "Quantum GIS"), que é um software livre/open source multiplataforma de sistema de georreferenciamento (GIS) que provê visualização, edição e análise de dados georreferenciados.
}

Revista Eletrônica: Tempo - Técnica - Território, V.7, N.2 (2017), 32:50 ISSN: 2177-4366 
acontecia na cidade, ficava-se sabendo. Os mapas foram produzidos no intuito de constituir, em parte, a visibilidade de ações feministas em suas diferentes expressões na cidade de Goiânia.

Para que os mapas fossem reconhecidos entre as entrevistadas, após todas as etapas mencionadas acima do mapeamento, foram propostos encontros com todas as mulheres, chamados de “Café com cartografias feministas”.

No primeiro encontro, após uma apresentação e explicação sobre a pesquisa e os mapas impressos em diferentes tamanhos, foram realizadas as seguintes perguntas para as mulheres presentes: se elas mudariam as simbologias e as cores escolhidas pela pesquisadora? Como o mapa partiu de pessoas e coletivos diferenciados, se elas inseririam locais ou lugares de conflitos e coalizões entre elas? Teriam, assim, simbologias de tensões? Devería-se inserir mais pontos e/ou trajetos importantes ou mudar algo nos mapas? E por último, como os mapas poderiam ser usados como ferramentas para as lutas feministas na cidade?

Após o encontro, foram adicionados e atualizados alguns pontos e trajetos nos mapas. Assim como algumas simbologias da legenda deles. E quando perguntadas sobre os possíveis locais de conflitos entre elas e seus grupos, as mulheres decidiram em conjunto não os evidenciar, argumentando que os mapas seriam acessados por diferentes pessoas e a intenção era mostrar as alianças e não os conflitos, apesar de eles existirem.

No encontro, as entrevistadas disseram que o mapa será utilizado como ferramenta para: fortalecer os movimentos feministas da cidade ao apresentar e localizar as ações; mostrar às mulheres as diferenças existentes entre as ações feministas e suas espacialidades de acordo com as características dos grupos e das militantes; conhecer as atuações de outras feministas e grupos de Goiânia; e trazer a discussão sobre a importância de se pensar espacialmente as suas ações.

\section{Resultados: Mapeando a cidade de Goiânia}

Fundada em 1933, a cidade de Goiânia possui - de acordo como o IBGE em 2014 aproximadamente 1.412.364 habitantes e com uma Região Metropolitana composta por vinte municípios (Lei Complementar Estadual de número 78, 25/03/2010), dos quais Aparecida de Goiânia, Senador Canedo e Trindade são os mais próximos e populosos. O centro da capital, correspondente à parte do planejamento inicial da cidade, abriga serviços - públicos e privados, a exemplo da sede do poder político estadual, hotéis, comércio e alguns parques. A exemplo de outras cidades brasileiras, não são perceptíveis a função e o uso predominantemente feminino e/ou feminista do espaço urbano. A Figura 1 corresponde ao mapa de localização do estado de Goiás e o município de Goiânia. 
Figura 1. Mapa de localização do município de Goiânia- Goiás, Brasil Fonte: Base cartográfica: IBGE, 2010.

Os movimentos feministas em Goiás (Brasil) surgem nos anos de 1980 com a formação de entidades de mulheres em Goiânia, a exemplo do Grupo Eva de Novo (1981), Centro Popular da Mulher em Goiás (1985) e Grupo Transas do Corpo (1987), e, posteriormente, na década de 1990, mulheres negras criam suas organizações: Associação Pérola Negra (1993), Malunga (1999) e Dandara no Cerrado (2002).

Durante as entrevistas, as mulheres trouxeram os locais na cidade que consideravam de diferenciadas formas e tempos importantes para os feminismos, para suas vivências, lutas, visibilizações e para as espacializações efêmeras ou não das atividades dos grupos que elas participam. A Figura 2 corresponde às ações que ocorreram durante a pesquisa, no chamado tempo presente (período entre os anos de 2013 a 2015) e estão mapeadas também ações passadas (entre os anos de $1985^{2}$ a 2013) e futuras (após 2015).

\footnotetext{
${ }^{2}$ Ano de criação do Centro Popular da Mulher em Goiás (CPM), cujo grupo é o mais antigo entre os que as entrevistadas participam e participaram.
}

Revista Eletrônica: Tempo - Técnica - Território, V.7, N.2 (2017), 32:50 ISSN: 2177-4366 


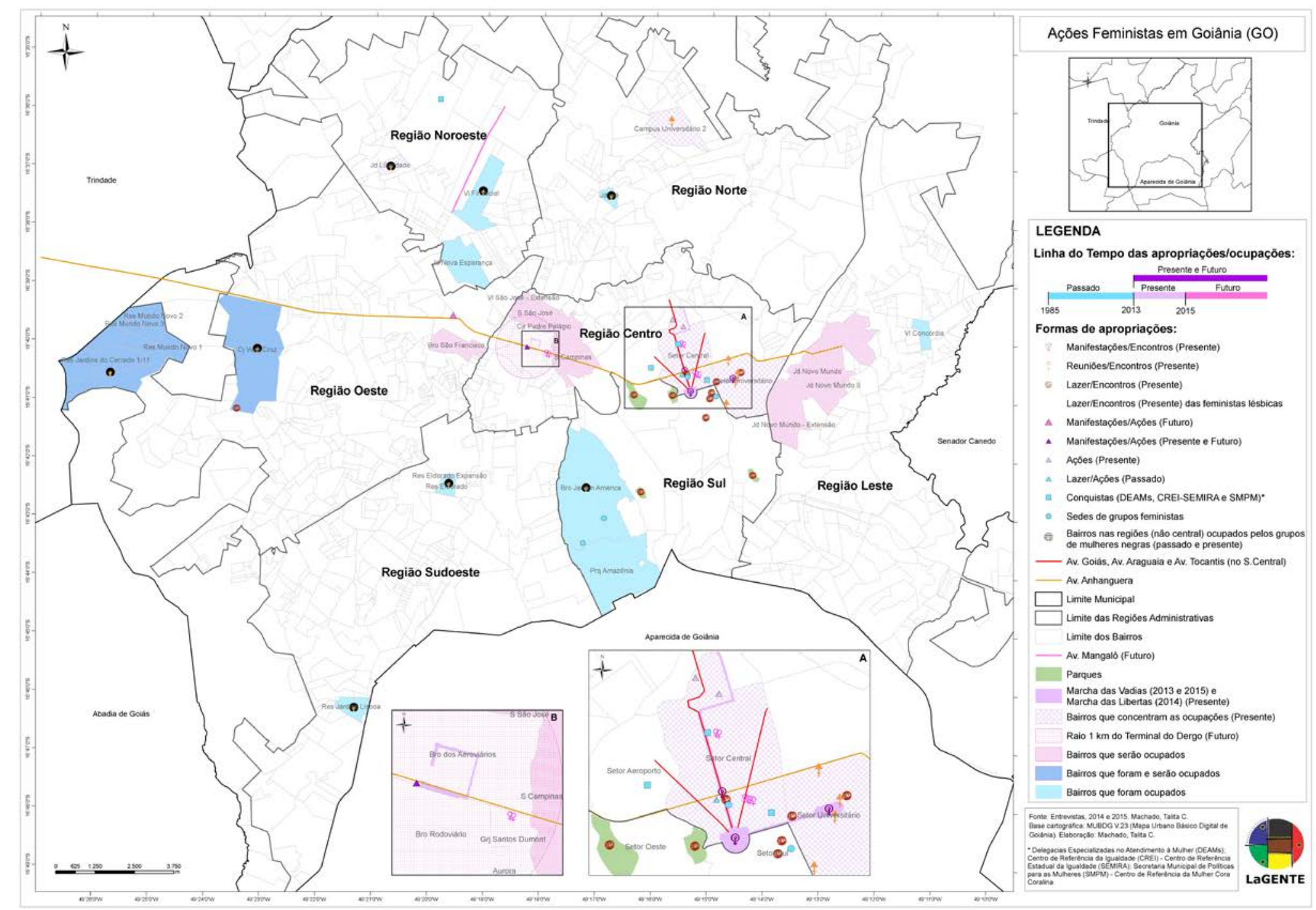

Figura 2. Ações feministas em Goiânia (GO)

Fonte: MACHADO (2017, p. 115)

Revista Eletrônica: Tempo - Técnica - Território, V.7, N.2 (2017), 32:50 ISSN: 2177-4366 
O Quadro 1 apresenta algumas simbologias utilizadas nos mapas e a explicação da escolha de cada uma delas pelas mulheres e de seus significados.

Quadro 1: Simbologias utilizadas nos mapas.

Fonte: Entrevistas 2014-2015 e Encontro “Café com cartografias feministas”, 2016.

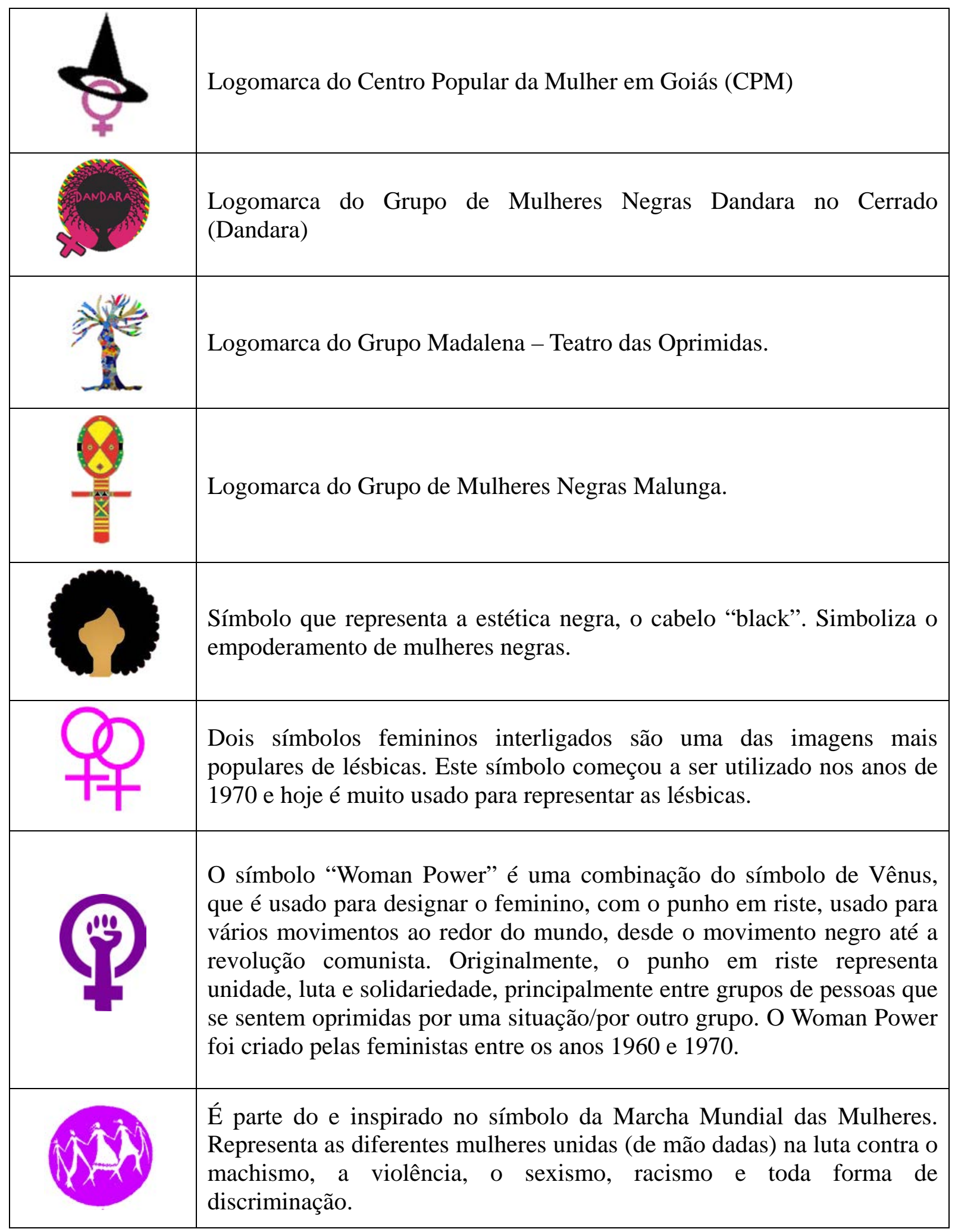

Revista Eletrônica: Tempo - Técnica - Território, V.7, N.2 (2017), 32:50 ISSN: 2177-4366 
Um dos limites do mapa (Figura 2) corresponde à escolha da escala municipal, pois as apropriações urbanas de algumas entrevistadas e de seus grupos extrapolam os limites do município e se expandem para a região metropolitana. Locais no município de Aparecida de Goiânia, localizados ao sul e cornubado com a área urbana de Goiânia, são apropriados por algumas feministas e seus grupos e são vistos por elas como locais periféricos.

As mulheres levam em conta as lógicas de organização da cidade em diferentes regiões político-administrativas e de suas especificidades para planejar e organizar suas ações (individuais e/ou coletivas), assim como as diferenciações entre centro e periferia. A seguir será apresentado algumas das ações que ocorrem em cada região de Goiânia.

\section{As ações feministas nas diferentes regiões da cidade}

Os órgãos de planejamento já estabeleceram, ao longo da história do município, várias formas de regionalização de Goiânia. A última regionalização estabelecida pela Prefeitura e presente no Anuário Estatístico de Goiânia (2012) redistribui a cidade em sete regiões ${ }^{3}$ : central ou central e campinas; leste; sul; oeste; sudeste; norte e noroeste. Essa foi a regionalização utilizada na construção da Figura 2.

A Figura 3 abaixo é um recorte do mapa da Figura 2 (com a adição de algumas informações) e corresponde às ações feministas realizadas na região central da cidade.

3 Prefeitura Municipal de Goiânia - SEPLAM / DPESE / DVPEE. Anuário Estatístico Goiânia, 2012.

Revista Eletrônica: Tempo - Técnica - Território, V.7, N.2 (2017), 32:50 ISSN: 2177-4366 


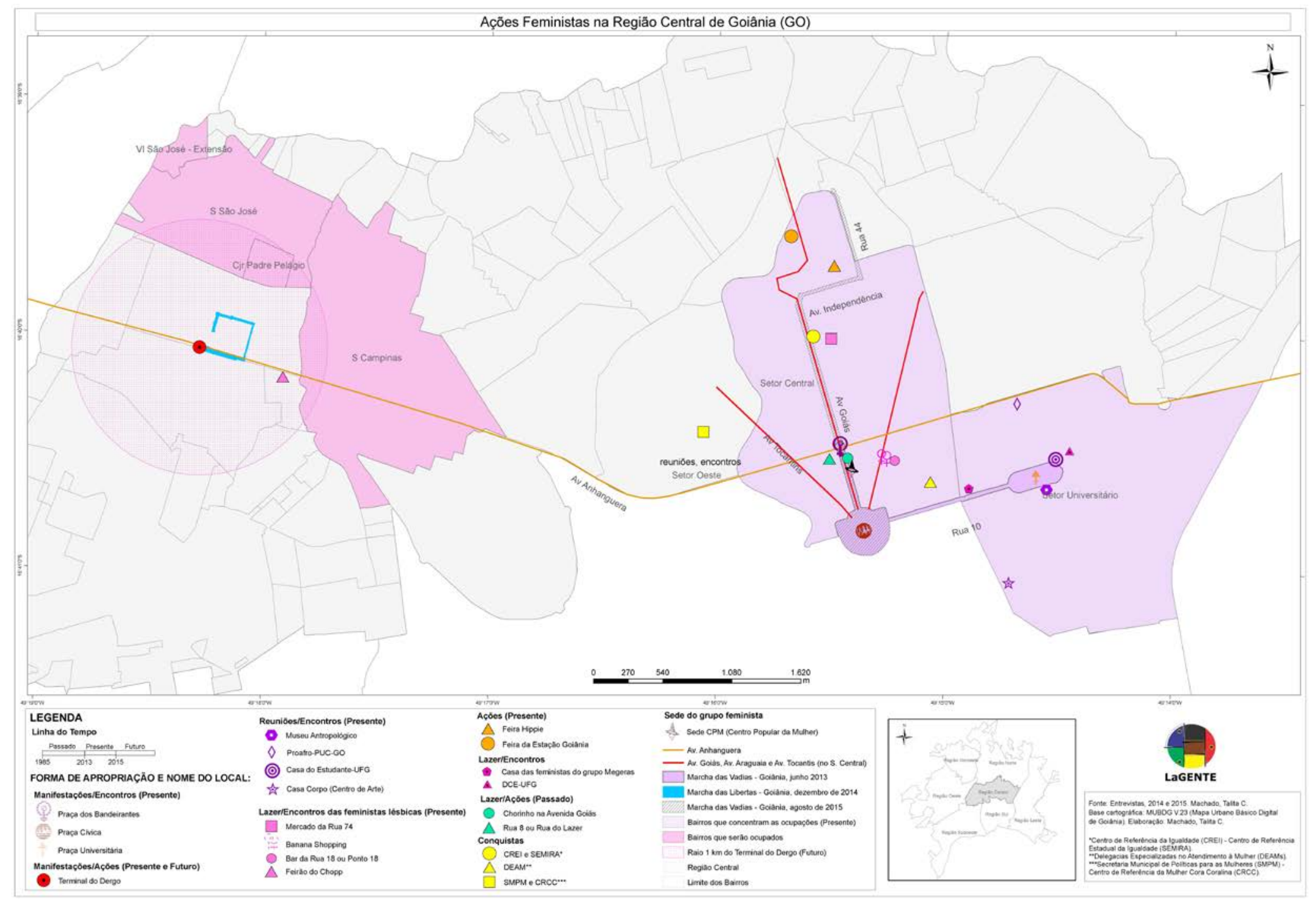

Figura 3. Ações feministas na região central de Goiânia (GO)

Fonte: MACHADO (2017, p.128)

Revista Eletrônica: Tempo - Técnica - Território, V.7, N.2 (2017), 32:50 ISSN: 2177-4366 
Na região central, o Setor Central e o Setor Universitário foram os bairros mencionados pelas mulheres como importantes. Foram trazidos como locais essenciais para os encontros e lazer (militante) entre as feministas mais jovens e acadêmicas. O Setor Central (ou centro) foi levantado por todas as entrevistadas como importante para dar visibilidade, através da mídia e das pessoas que estão de passagem naquele local, às manifestações dos grupos.

As praças localizadas nesses setores foram trazidas como locais importantes, principalmente a Praça Cívica, a Praça Universitária e a Praça dos Bandeirantes. Estes três locais onde, historicamente, são de grande circulação, de mobilização política e que podem ter a presença da mídia, concentram algumas manifestações. Os trajetos que interseccionam as três praças são de fundamental importância para os feminismos construídos pelas mulheres.

A Praça dos Bandeirantes hoje não é mais praça, e sim um cruzamento entre duas avenidas principais da cidade, Avenida Anhanguera e Avenida Goiás. Ela é historicamente um lugar das ações dos movimentos sociais e de protestos em Goiás. Apesar de não existir mais como praça, a Praça dos Bandeirantes ainda é a ágora dos movimentos sociais, é local importante para os feminismos. As escolhas dos locais para ocorrer todos os tipos de manifestações e encontros entre as feministas na região central da cidade são políticas e orientadas.

A Praça Cívica está entre as Avenidas Goiás, Tocantins e Araguaia e é onde está o Palácio Pedro Ludovico e grande parte da estrutura administrativa estadual. Quase todas as caminhadas, manifestações dos grupos feministas, saem ou passam por essa praça.

As feiras na região central, principalmente a Feira Hippie e a Feira da Estação, foram trazidas de forma díspar pelas entrevistadas. Algumas não as trouxeram como locais de grande importância para as ações feministas que já ocorrem. Para elas, as feiras são lugares que não funcionam enquanto local de manifestação. Diferentemente, os grupos das mulheres feministas negras veem as feiras como espaços de vivências entre as mulheres negras e dizem ser um importante local para ser apropriado por elas.

As praças são lugares de anúncio, de comunicação, de passagem e, principalmente, de vivências, como durante os encontros que ocorrem nelas, por exemplo, as trocas e os piqueniques feministas, cuja maioria das participantes é mulher jovem e/ou possui alguma relação com a academia.

As feministas, em especial as jovens lésbicas e bissexuais, trouxeram lugares, como por exemplo, o Mercado da Rua 74 (ou Mercado Popular), o Feirão do Chope ${ }^{4}$, o Bar da Rua 18 (ou Ponto 18) e o Banana Shopping, todos na área central, como locais importantes para seus momentos

\footnotetext{
${ }^{4}$ É um local LGBT (Lésbicas, Gays, Bissexuais e Travestis) da cidade de frequentação noturna, situado numa área periférica, que existe há mais de 10 anos . (HAMMES, 2015)

Revista Eletrônica: Tempo - Técnica - Território, V.7, N.2 (2017), 32:50 ISSN: 2177-4366
} 
de lazer e para ocupação coletiva das mulheres. São locais onde elas se sentem bem em relação às suas sexualidades e outras identidades.

As ruas da região central foram trazidas pelas mulheres como importantes e algumas delas, já foram lugares de vivências feministas, como a Rua 8 e o Projeto Grande Hotel Vive o Choro (conhecido como o Chorinho), da Secretaria Municipal de Cultura de Goiânia, que acontecia na Avenida Goiás, ambas, no Setor Central.

A Rua 8, conhecida também como Rua do Lazer, apareceu nas falas das feministas que tinham entre 44-67 anos de idade. Este local foi intensamente ocupado por elas, principalmente nas décadas de 1980, 1990 e 2000:

As sedes de alguns grupos feministas, localizadas na região central, foram trazidas como importantes conquistas dos movimentos, como as: do CPM (Centro Popular da Mulher); do Fórum Goiano de Mulheres e da Assessoria Municipal da Mulher. Nesses lugares ocorrem e/ou ocorriam as formações feministas, as vivências e as construções de feminismos em Goiânia.

Os locais constituídos a partir das lutas feministas na cidade também foram mencionados, principalmente pelas mulheres entre 44-67 anos de idade que participaram destas conquistas, como o Centro de Referência da Igualdade (CREI) da Secretaria Estadual da Mulher, do Desenvolvimento Social, da Igualdade Racial, dos Direitos Humanos e do Trabalho (SEMIRA), o Centro de Valorização da Mulher (CEVAM) e as Delegacias Especializadas no Atendimento à Mulher (DEAM), uma localizada no Setor Central e a outra no Jardim Curitiba II (na região noroeste).

As mulheres levam em conta as diferenciações entre centro e periferia para realizar suas ações. Importante destacar que existem áreas segregadas ${ }^{5}$ também nas regiões centrais e sul de Goiânia.

As cidades brasileiras tiveram suas estruturas urbanas orientadas pela relação centroperiferia. Cujas áreas centrais eram equipadas de melhor infraestrutura e a periferia era vista como uso residencial da população com menor nível de renda. Mas as mudanças que vêm passando as cidades, muitas vezes movidas pelos interesses imobiliários e fundiários, têm transformado também a estrutura centro e periferia.

O termo periferia é usado não apenas no sentido de localização, mas social, designando bairros nos quais estão ausentes os serviços básicos (luz, água, esgoto, calçamento, transporte, escola, posto de atendimento médico), situação encontrada também no “centro”, isto é, nos bolsões de pobreza, nas favelas ou nos “aglomerados subnormais”, que segundo o IBGE:

\footnotetext{
5 “[...] a segregação é um processo segundo o qual diferentes classes ou camadas sociais tendem a se concentrar cada vez mais em diferentes regiões gerais ou conjuntos de bairros da metrópole.” (VILLAÇA, 2001, p. 142, grifo do autor).

Revista Eletrônica: Tempo - Técnica - Território, V.7, N.2 (2017), 32:50 ISSN: 2177-4366
} 
(...) podem se enquadrar, observados os critérios de padrões de urbanização e/ou de precariedade de serviços públicos essenciais, nas seguintes categorias: invasão, loteamento irregular ou clandestino, e áreas invadidas e loteamentos irregulares e clandestinos regularizados em período recente. (IBGE, 2010, p.19).

Villaça (2001) afirma que uma das características mais marcantes das metrópoles brasileiras é a segregação espacial das classes sociais em áreas distintas da cidade (não necessariamente nas áreas geograficamente periféricas). A diferenciação entre os bairros diz respeito ao perfil da população, como das características urbanísticas, de infraestrutura, de conservação dos espaços e equipamentos públicos, etc.

O Terminal do DERGO (Departamento de Estrada e Rodagem), localizado na antiga região Campinas e hoje região central, é visto pelas mulheres como um local periférico no centro. Ele está localizado próximo aos bairros que possuem muitos “aglomerados subnormais” (IBGE, 2010, p.19). A área próxima ao DERGO é conhecida como uma das maiores zonas de prostituição de Goiânia, onde atuam diferentes profissionais do sexo, a maioria, de classe baixa e com mais de 35 anos de idade, podendo ser encontradas idosas com idade entre 60 e 70 anos. E é, ao mesmo tempo, uma área onde muitas mulheres são violentadas e assassinadas na cidade.

O Terminal do DERGO foi trazido como local importante para as atuações dos movimentos. Numa tentativa de expandir os locais de manifestações para além do Setor Central e Universitário, o Terminal e a área ao seu redor foram trazidos como locais “problemáticos” no que diz respeito às questões de gênero e sexualidade e que necessitam de uma importante atuação dos grupos.

Ocorreu em 2014, a terceira Marcha das Vadias em Goiânia, chamada nesse ano de Marcha das Libertas e pela primeira vez o local escolhido para a concentração foi o Terminal do DERGO. A mudança do nome da Marcha ocorreu após várias discussões entre as participantes com o objetivo de ele estar mais próximo às demandas das mulheres profissionais do sexo daquela região. Isso exemplifica os processos pelos quais passam alguns grupos feministas da cidade, em pensar espacialmente e estrategicamente outros locais para as ações e apropriações no espaço urbano.

Para as mulheres acadêmicas e mais jovens, as conquistas devem avançar para a periferia de Goiânia (regiões noroeste, leste, oeste e sudeste). Apesar da violência contra a mulher está em todos os lugares, elas acreditam que os movimentos feministas devem priorizar agora as(os) moradoras(es) da periferia.

Na Figura 2 observa-se que os bairros e locais onde serão futuramente ocupados, através de ações dos grupos feministas ligados à academia, estão próximos ou são cortados pela Avenida Anhanguera ou Eixo Anhanguera ${ }^{6}$. Esses bairros e locais foram trazidos pelas mulheres que

\footnotetext{
${ }^{6}$ O Eixo Anhanguera é o nome dado a um corredor de transporte coletivo exclusivo, na modalidade BRT, localizado Revista Eletrônica: Tempo - Técnica - Território, V.7, N.2 (2017), 32:50 ISSN: 2177-4366
} 
transitam por eles diariamente e/ou os vivenciam, mulheres que moram em áreas periféricas da cidade e que utilizam o Eixo para se deslocarem na cidade, ou seja, correspondem aos trajetos diários de algumas entrevistadas.

Os bairros mais periféricos nas regiões oeste, leste e central, como Jardim do Cerrado 1 ao 11, Residencial Mundo Novo 1 ao 3, Conjunto Vera Cruz, Setor São José, Vila São José Extensão, Conjunto Padre Pelágio, Setor Campinas, Bairro São Francisco e Jardim Novo Mundo e o Terminal Padre Pélágio (Bairro Ipiranga e Bairro Capuava), destacados na Figura 2, foram mencionados pelas mulheres como estratégicos para ocupações futuras dos movimentos feministas. Nestes bairros a população é majoritariamente negra e possui rendimentos baixos, segundo Censo 2010 (FERREIRA, 2014).

Enquanto as mulheres jovens ligadas aos movimentos feministas acadêmicos estão iniciando a discussão sobre expandir suas ações para a periferia da cidade, e esse discurso está mais presente nas falas das mulheres que moram em e/ou se originam de locais periféricos e que estão na universidade, algumas feministas entre 44-67 anos, disseram que as ações passadas, organizadas pelos grupos que elas participavam, tinham como foco os bairros localizados mais na periferia. Algumas entrevistadas disseram que as reuniões e ações eram realizadas nos bairros mais periféricos da cidade e essa era uma prática de vários grupos (feministas, de esquerda etc.) iniciada antes do ano de 1984, devido a existência da Ditadura Militar. Pois, durante a Ditadura (19641984), o centro da cidade foi intensamente monitorado pelos militares, que não permitiam os encontros e reuniões de muitos movimentos sociais.

Já os grupos de mulheres negras atuam, desde sua criação, na periferia. Eles foram criados pensando as apropriações da periferia, por meio de vivências e de vários projetos.

Outros locais mencionados pelas feministas foram as escolas das periferias e as casas das mulheres, vistas como locais importantes para vivências entre elas.

As feiras, tanto da região central como periférica da cidade foram trazidas como locais relevantes. Nas feiras localizadas em áreas centrais, o público alvo são as feirantes, e na periferia, são principalmente, as mulheres que fazem as feiras. As feiras do centro, que foram trazidas pelas feministas, comercializam predominantemente, roupas, calçados e acessórios. Já as feiras nas áreas periféricas, onde atuam os feminismos de grupos de mulheres negras e/ou de periferia, comercializam, principalmente, alimentos (frutas, verduras, etc.).

em Goiânia. Possui 14km de extensão, faz a ligação entre os extremos leste e oeste da capital, através da Avenida Anhanguera, uma das mais importantes da cidade. Ao longo de seu percurso, compreendido entre os Terminais Padre Pelágio (Bairro Ipiranga) e Novo Mundo (Setor Novo Mundo), atravessa mais três terminais de integração (Terminal DERGO, Terminal Praça "A" e Terminal Praça da Bíblia), que fazem a conexão com grande parte das demais regiões de Goiânia.

Revista Eletrônica: Tempo - Técnica - Território, V.7, N.2 (2017), 32:50 ISSN: 2177-4366 
Na região sul, as mulheres jovens e acadêmicas trouxeram os parques ambientais, com grande circulação de pessoas nos finais de semana, que são os: Bosque dos Buritis (Setor Oeste), Parque Lagoa das Rosas (Setor Oeste), Parque Vaca Brava (Setor Bueno) e o Parque Flamboyant (Jardim Goiás). Estes são os locais onde acontecem as intervenções urbanas feministas que são momentos de encontros entre as mulheres e os vários grupos e acontecem em espaços públicos da cidade. Durante as intervenções, ocorrem as rodas de conversas, oficinas, piqueniques, feira de trocas, peças de teatro etc., sempre com temas voltados para as mulheres.

As sedes do grupo Madalenas e de mulheres negras Malunga e Dandara do Cerrado, localizadas na região sul, foram trazidas pelas entrevistadas como locais de referências feministas.

Na região central, as apropriações feministas são realizadas de forma mais intensa nos espaços púbicos, como a praça, as ruas e os parques ambientais. Já na periferia, os espaços das casas, das escolas e das associações de moradores são os lugares mais importantes para realizar as apropriações. Isso nos diz da diferença dos usos dos espaços públicos no centro e em áreas periféricas.

Na região norte, a Universidade Federal de Goiás estava presente nas falas das entrevistadas como um local importante para as ações feministas no sentido delas estarem presentes e atuando, tanto organizadas em grupos e coletivos ou através de suas trajetórias individuais, como alunas, professoras etc. A UFG é vista como um local onde estão presentes, de forma fluida, as conquistas feministas e como sendo a casa dos movimentos sociais, por também dar apoio físico aos grupos para realizarem as reuniões, encontros, oficinas, etc., que ocorrem de forma intermitente, temporárias e móveis dentro da universidade.

Foram apresentados e discutidos alguns locais mapeados na Figura 2, e concluiu-se que existem lugares onde apenas alguns grupos específicos feministas atuam (como por exemplo, as mulheres negras que atuam nas regiões periféricas) e outros, onde todos eles estão presentes (a exemplo, o setor Central).

\section{Considerações Finais}

Os mapas resultantes deste trabalho evidenciam os locais e percursos das ações das entrevistadas e seus coletivos na cidade e possibilita iniciar uma reflexão de como as feministas vivenciam esses lugares e organizam suas ações.

A importância desta pesquisa corresponde ao mapeamento não dominante nos estudos presentes em geografia urbana e nos planejamentos e estudos sobre a cidade. Ela traz à tona "os Revista Eletrônica: Tempo - Técnica - Território, V.7, N.2 (2017), 32:50 ISSN: 2177-4366 
pontos cegos” (MASSEY, 2008, p.164) nos mapas dominantes da cidade, ou seja, os locais importantes na cidade para a luta de grupos feministas e possibilita iniciar uma discussão sobre a relação entre a questão de gênero e a cidade.

Sugere-se que os mapas construídos por sujeitos(as) e grupos subalternizados(as) possam compor o conjunto de mapas utilizados para o planejamento da cidade de Goiânia.

Concorda-se com o pensamento da geógrafa Calió (1997) quando ela afirma que é só feminilizando os conceitos de Planejamento e a prática das Políticas Públicas que será possível dar verdadeira dimensão ao conceito de "cidadania e democracia", ou seja, só construindo estratégias que melhorem a vida das mulheres e que "levem em conta sua especificidade, incorporando as como grupo prioritário no combate à discriminação.” (p.8).

Os mapas construídos serão usados pelas próprias feministas para análise espacial de suas ações e de outros grupos e mulheres, mas recomenda-se que eles possam também estar presente na construção de políticas públicas para as mulheres na cidade e empregados como ferramentas para a análise sobre o espaço urbano que leve em consideração as singularidades e especificidades das vidas das mulheres.

\section{Referências Bibliográficas}

ACSELRAD, H. Apresentação. In: ACSELRAD, Henri (org.). Cartografia social e dinâmicas territoriais: marcos para o debate. Rio de Janeiro: Universidade Federal do Rio de Janeiro, Instituto de Pesquisa e Planejamento Urbano e Regional, 2010.

CALIÓ, C. A. Incorporando a Questão de Gênero nos Estudos e no Planejamento Urbano. In: 6º Encontro de Geógrafos de América Latina. Buenos Aires, Argentina, 1997. Anais. Disponível em: $<$ http://observatoriogeograficoamericalatina.org.mx/egal6/Geografiasocioeconomica/Geografiacultural/ 737.pdf > Acesso em 20 de mai de 2016.

FERREIRA, D. C. Diferenciação e Segregação Racial em Goiânia: Representação Cartográfica dos dados de cor ou raça e renda (IBGE, 2010), 2014. Dissertação (mestrado em Geografia) IESA/UFG, Goiânia - GO, 2014.

HAMMES, B. dos S. No Feirão do Chope: Um estudo antropológico sobre intersecções entre marcadores sociais da diferença em um bar na região periferizada de Goiânia, 2015. Dissertação (mestrado em Antropologia Social) PPGAS/UFG, Goiânia - GO, 2015. 
HUGGAN, G. Decolonizing the map: post-colonialism, post-struturalism and cartographic connection. Ariel, vol. 20, n. 4, 1989.

IBGE/SIDRA. Sistema IBGE de Recuperação de Recuperação Automática. Rio de Janeiro, 2010.

Disponível em: <http://www.sidra.ibge.gov.br/> . Acesso em 15 de mar. de 2014.

MACHADO, T. C. A cidade das mulheres feministas [manuscrito]: Uma cartografia de Goiânia em perspectiva interseccional e da diferença. 2016. 231 f. Tese (doutorado em Geografia) Universidade Federal de Goiás, Goiânia, 2016.

MARTINELLI, M. As representações gráficas da geografia: os mapas temáticos. 1999. Tese (Livre Docência em Geografia). Faculdade de Filosofia, Letras e Ciências Humanas, Universidade de São Paulo, 1999.

MASSEY, D. Pelo Espaço. Uma Nova Política da Espacialidade. Rio de Janeiro: Bertrand Brasil, 2008.

MOREIRA, R. O Pensamento Geográfico Brasileiro, v. 1: as matrizes clássicas originárias. São Paulo: Contexto, 2008.

SANTOS, R. E. N. Dos. Ensino de geografia e currículo: questões a partir da lei 10.639. In: Terra Livre. São Paulo, ano 26, v.1, n.34, p. 141-160, jan.-jun.2010.

VILLAÇA, F. Espaço Intra-Urbano no Brasil. São Paulo: Studio Nobel: FAPESP: Lincoln Institute, 2001. 
Título: Construindo mapas feministas da cidade de Goiânia (GO)

Autora: Talita Cabral Machado

Doutora em Geografia pela Universidade Federal de Goiás. Geógrafa na Diretoria de Informações Urbanas e Geoprocessamento da Secretaria Municipal de Planejamento Urbano de Goiânia.

Endereço: Quadra 22 - Lote 49 - Setor Leste, Gama - DF. CEP: 72460220

E-mail: talita.geo@gmail.com

Órgão Financiador da pesquisa: Coordenação de Aperfeiçoamento de Pessoal de nível superior (CAPES) 